\title{
Multi-level Fuzzy Comprehensive Evaluation of Public Transport Satisfaction in Wuhan Area
}

\author{
Chunxiao Zhang \\ Jianghan University \\ Wuhan, China
}

\author{
Yihong $\mathrm{Xu}$ \\ Jianghan University \\ Wuhan, China
}

\begin{abstract}
Wuhan's long-term plan is to build a great city of National center with population exceeding ten million. Public transportation plays an important role in relieving urban traffic pressure and improving the ability of collecting passengers. However, due to the low satisfaction of Wuhan middle and high income group to the public traffic in Wuhan City, more and more residents choose private car to travel, which leads to quite a few problems, such as fewer cars, traffic jams, parking difficulties and environmental pollution. With the growing scale of Wuhan and the improvement of people's living standards, the urban problems caused by private traffic crowding out public transportation will become more and more prominent. The key to resolving this dilemma is to increase public satisfaction with public transport, giving priority to public transport and reducing the use of private transport. In order to study the satisfaction and influence factors of Wuhan residents to the public traffic in Wuhan, and to provide policy suggestions for optimizing the development of the public transport, the report makes a survey, measurement, and analysis of public transport satisfaction in Wuhan. By using the unequal probability three-stage sampling method, the fuzzy analytic hierarchy process satisfaction measure and the comprehensive evaluation method, the difference of the satisfaction degree of different groups to the public traffic is studied. The conclusion is reached that the highest level of satisfaction of public transport is among the elderly and those who have the annual income of 80000 to 140000 RMB.
\end{abstract}

Keywords-public transport; satisfaction; fuzzy analytic Hierarchy Process

\section{INTRODUCTION}

Generally speaking, public transport has two interpretations: broad sense and narrow sense. Broadly speaking, public transport is including civil aviation, railways, highways, water transportation and other means of transport, the narrow sense of public transport refers to the city scope of the bus and rail transit, ferry, ropeway and other means of transport. But in either case, public transport is the main way of people's daily travel.

Public transport is an important place in the development of urban planning. At present, the public transport in Wuhan is showing a trend of prosperity and development. In 2016, there are 557 buses in Wuhan. The subway lines under construction in Wuhan are up to 13 , and 5 years later, about 11 new subways lines will open. Today, there are more than 10 ferries between the three towns in Wuhan, with 20 auxiliary wharves such as Wuhan Guan, Qingchuan and so on. Nevertheless, the growth and development of public transport cannot completely solve the traffic problems in Wuhan, such as traffic congestion, environmental pollution. If the satisfaction of Wuhan residents with public transport can be improved, they will be able to consolidate the regular passengers of public transport and make more and more residents choose public transportation as the main way to travel. This paper will focus on the residents' needs and study the residents ' satisfaction to public transportation.

\section{A. Summary of Traffic Congestion in Wuhan City}

Facing the current situation of traffic congestion in Wuhan, the research is mainly carried out in the following aspects: ( 1 ) Based on the principle of analytic hierarchy process, a model of urban traffic congestion evaluation is established (Lee Roming 2005); ( 2 ) Taking Wuhan traffic status as the research object, the influence of traffic jam on urban sustainable development is discussed. (Deng Juan, Zhang, Ching (2011 )); ( 3 ) From the perspective of scarcity of space resources, the present situation of urban traffic congestion is studied.(Gall, Zhao ( 2007 )).

\section{B. Overview of Building Satisfaction Assessment Models}

In the domestic, the concept of satisfaction is introduced late, so our country has just started in either the satisfaction of the theoretical exploration or satisfaction of the application of practical aspects. Its research is mainly carried out from the following aspects: ( 1 ) Exploring about how to construct the model of satisfaction evaluation reasonably and establishing the evaluation model of the Fuzzy Comprehensive evaluation Method (Vurong( 2009 )); ( 2 ) Researching on government performance evaluation guided by satisfaction (Xu Huicai (2010)); ( 3 )Breaks down integrated services into multiple resident satisfaction attributes, satisfaction with individual satisfaction attributes by resident population, overall satisfaction with a city's transport services. "(Wu Hongyang(2008)).

Based on the analysis of the above two aspects, it can be seen that all kinds of urban public transportation which are convenient for the citizens to travel is a kind of public goods, and the rational use and distribution of the resources of public goods are helpful to improve the residents ' life satisfaction and promote the construction of a harmonious and civilized society. Wuhan, as an oversized city in central 
China, has an urgent need to explore efficient and convenient urban public transport mode under the condition of a good geographical location, rapid economic development and an environment in urgent need of improvement.Therefore, this study will take the residents' demand of public transport as a starting point, and construct the evaluation system of residents' Satisfaction with the analytic Hierarchy Process fuzzy comprehensive evaluation method.

\section{RESEARCH AND DESIGN}

The research object of the study is the general population of Wuhan Urban residents. A total of 1285 questionnaires is issued, valid questionnaires were 1056 , accounting for $82.18 \%$.

\section{A. Survey Methodology}

Investigate the method of adopting unequal probability three-stage stratified sampling.

- First stage: stratified sampling, unequal probability sampling

From the Statistical Yearbook downloaded by the Wuhan Bureau of Statistics, Wuhan has totally 13 districts, including 7 central cities -Jiangan District, Jianghan District, Qiaokou District, Wuchang, Hongshan District, Qingshan District , and 6 far urban districts -Dongxihu District, Caidian District, Jiangxia District, Huangbei District, Xinzhou District, Hannan. Therefore, the study will be divided into two levels, that is, the central and far urban areas.

- Second stage: stratified sampling, equal probability sampling

Taking the central urban layer as an example, the second stage of sampling is to extract two units from the sampling frame of level two units, that is, to extract the sample communities from each of the selected administrative layers. Because the number of people in each administrative district is different, the weights are determined by the proportion of each administrative district, a stratified sampling is taken to determine the number of communities in each administrative district.

\section{- Phase III: System sampling}

The third stage is to extract the respondents from the sample community in the form of street-blocking surveys.

\section{B. Determination of Sample Size}

We take the questionnaire, whose degree of the total satisfaction of Wuhan public transportation is equal or greater than "satisfaction", as a research objects. So we pay attention to the sample variance of the overall satisfaction and the ratio. The formula for calculating the optimal sample size without correction is

$$
n_{0}=\frac{t^{2} P Q i d^{2}}{1+\frac{1}{N}\left[\frac{t^{2} P Q}{d^{2}}-1\right]}
$$

$\mathrm{N}$ is the overall number, when the confidence level is $95 \%, \mathrm{t}=1.96, \mathrm{P}$ is the sample scale, $\mathrm{D}$ is absolute Tolerance, $\mathrm{d}=0.04, \mathrm{p}=0.37$ from the results of pre-survey . In practice, if $\mathrm{P}$ is around 0.37 , the sample size can be calculated according to the maximum value of the total variance at $\mathrm{p}=0.37$, so the $\mathrm{p}=0.37$. As the total resident population in Wuhan, $\mathrm{n}=1060$ million, you can approximate the best sample size:

$$
n_{0}=\frac{t^{2} p(1-p)}{d^{2}}=\frac{1.96^{2} * 0.37 * 0.63}{0.04^{2}}=560
$$

Thus based on the sample size when a simple random sampling scale is $\mathrm{P}, 560$ is the best sample size with the absolute error of sampling less than $4 \%$ in the confidence of $95 \%$. Since our sampling scheme is complex, it is difficult to calculate the actual design effect Deff. Based on the combination of the preliminary investigation and literature, assuming that the design effect of the multi-stage sampling we take is 1.8 , the number of valid samples to be recycled is about 1000 .

$$
\mathrm{n}-\mathrm{n}_{0} * \text { deff }=560 * 1.8 \approx 1000
$$

Considering the facts that samples are invalid caused by the residents giving up to fill out the questionnaire halfway, or their being in the company investigation and other relevant units of the work, and other reasons, after collecting guidance teacher's opinion and experience, we assume that the invalid ratio is $20 \%$, the sample size that should actually be investigated is 1250 .

$$
n^{\prime}=n \div(1-0.2)=1250
$$

\section{DATA ANALYSIS}

After completion of the questionnaire design, we carry out a questionnaire on the 14 communities entering the sample based on the sampling frame. Each community issue is a questionnaire, a total of the 140 questionnaires. We recycle 140 questionnaires, and obtained 103 valid questionnaires after screening. According to the recycled questionnaire, the item analysis, reliability and validity of the date are carried out to check the identification degree of the questionnaire, the reliability of the results and the validity of the questionnaire.

\section{A. Analysis of the Discrimination:}

After finishing the collected questionnaires, the paper first makes an analysis of the classification of each item of the scale. The main purpose is to examine the scale of the preparation or to examine the reliability of individual items. This survey uses the high and low group average difference examination method to examine. The results show that the distinction of each item is set up reasonably.

\section{B. Reliability Analysis:}

This study uses SPSS, the statistical software analyzes the reliability of the data collected by the survey. The reliability analysis of three items of public transportation of 
subway, bus and taxi is made, and the results of the Cronbach coefficients are as follows:

TABLE I. RELIABILITY ANALYSIS

\begin{tabular}{|l|l|l|l|}
\hline & $\begin{array}{c}\text { Cronbach } \\
\text { Factor }\end{array}$ & $\begin{array}{c}\text { Number } \\
\text { of items }\end{array}$ & $\begin{array}{c}\text { Reliability } \\
\text { Analysis }\end{array}$ \\
\hline Bus & 0.866 & 10 & Good \\
\hline Subway & 0.919 & 10 & Good \\
\hline Taxi & 0.883 & 7 & Good \\
\hline
\end{tabular}

As results shows, the reliability coefficient of this questionnaire is 0.866 ; subway reliability coefficient is 0.919 ; the reliability factor for taxis is 0.883 , which indicate that the data obtained by this questionnaire is of higher reliability.

\section{Validity Check}

TABLE II. VALIDITY ANALYSIS

\begin{tabular}{|l|l|l|l|l|}
\hline & \multicolumn{1}{|c|}{$\begin{array}{c}\text { KMO } \\
\text { Factor }\end{array}$} & P value & $\begin{array}{c}\text { Number of } \\
\text { items }\end{array}$ & $\begin{array}{c}\text { Validity } \\
\text { analysis }\end{array}$ \\
\hline Bus & 0.864 & 0.000 & 10 & Good \\
\hline $\begin{array}{l}\text { Subwa } \\
\text { y }\end{array}$ & 0.861 & 0.000 & 10 & Good \\
\hline Taxi & 0.854 & 0.000 & 7 & Good \\
\hline
\end{tabular}

We use factor analysis method to test the structural validity of the questionnaire. Using SPSS to calculate the bus, subway, and taxi in the questionnaire KMO (kaiser-meyerolkin) coefficients are $0.864,0.861,0.854$, and $\mathrm{P}$ is 0.000 , which indicate that the questionnaire is structurally well designed.

\section{ANALYSIS OF THE SATISFACTION OF PUBLIC TRANSPORT IN WUHAN AREA}

\section{A. Analysis of Public Transport in Wuhan Area}

(1) Gender distribution. In a valid questionnaire collected from this survey, men account for $45.83 \%$, and women account for $54.17 \%$ of the total number of samples. (2) Age distribution. Among all respondents, the age of 20-29 accounts for $29.17 \%$ of the respondents, the age of $30-39$ $20.45 \%$, the age of $40-4918.56 \%$, under the age of 19 $13.64 \%$ and over the age of $5018.18 \%$. (3) Occupational distribution. Students in the school account for the $34.47 \%$; secondly, the proportion of average staff and teachers in the sample are $12.12 \%$ and $11.74 \%$ respectively; the number of freelancers, ordinary workers, self-employed persons and retirees is between 60 to 100 . (4) Income distribution. The annual income range of the sample group is mainly below 80 000RMB, and annual revenue is less than 20 000RMB, accounting for $52.37 \%$ of the sample. Annual income is between 30000 to $80000 \mathrm{RMB}$, accounting for $22.82 \%$ of the sample; the annual income ranging from 150000 to 200 000RMB and above 200 000RMB account for $3.69 \%$ and $3.79 \%$ respectively.

\section{B. Passenger Satisfaction Analyses in Wuhan}

According to the structure of the preliminary design questionnaire, the paper intends to evaluate the satisfaction of urban public transportation from many aspects, and we can choose the objective evaluation methods, such as factor analysis, cluster analysis and so on, and also the subjective evaluation methods, such as analytic hierarchy process and fuzzy comprehensive evaluation. In the analysis, we expect to get the index satisfaction of all aspects of urban transport without missing the impact of secondary factors, so we choose the fuzzy comprehensive evaluation. In the subjective evaluation method, how to minimize the influence of subjective factors is an important factor of the final result, so we use the analytic hierarchy process to set up the index and calculate the weight, combining the analytic hierarchy process with the fuzzy comprehensive evaluation, so as to reduce the influence of subjective assignment.

\section{Establishment of a Hierarchical Analysis Model}

The so-called analytic hierarchy process refers to make a complex multi-objective decision problem as a system, and the goal is decomposed into multiple targets or criteria, and then decomposed into several levels of multiple indexes (or criteria, constraints). The Hierarchical Order (weights) and total ordering are calculated by qualitative index fuzzy quantization, which is used as objective (multiple targets), the systematic method of multi-scheme optimization decision.

The steps to build the model are as follows:

- Based on the previous questionnaires, we set up the following graph hierarchy Analysis model: 


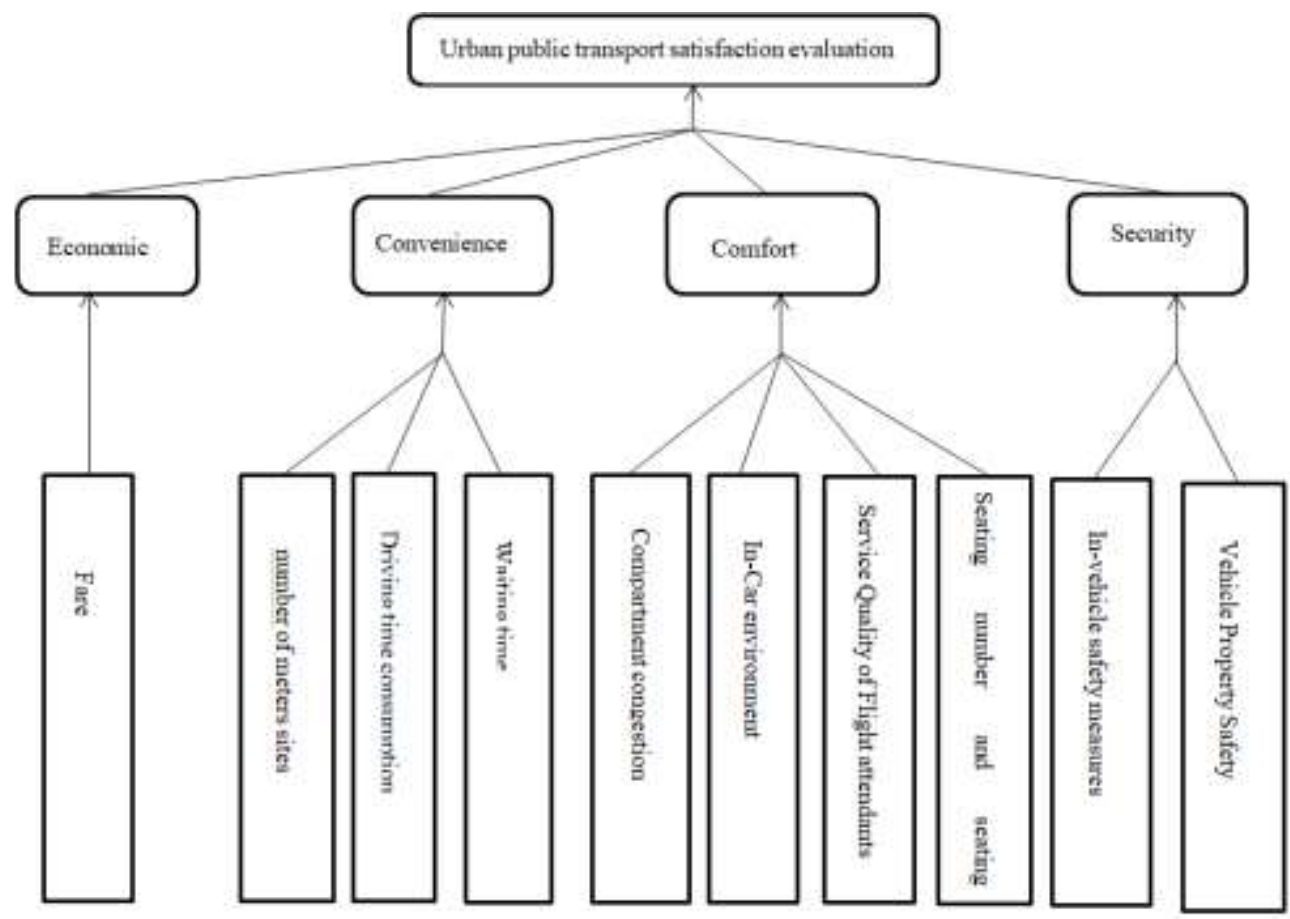

Fig. 1. The analytic hierarchy process model of bus and subway.

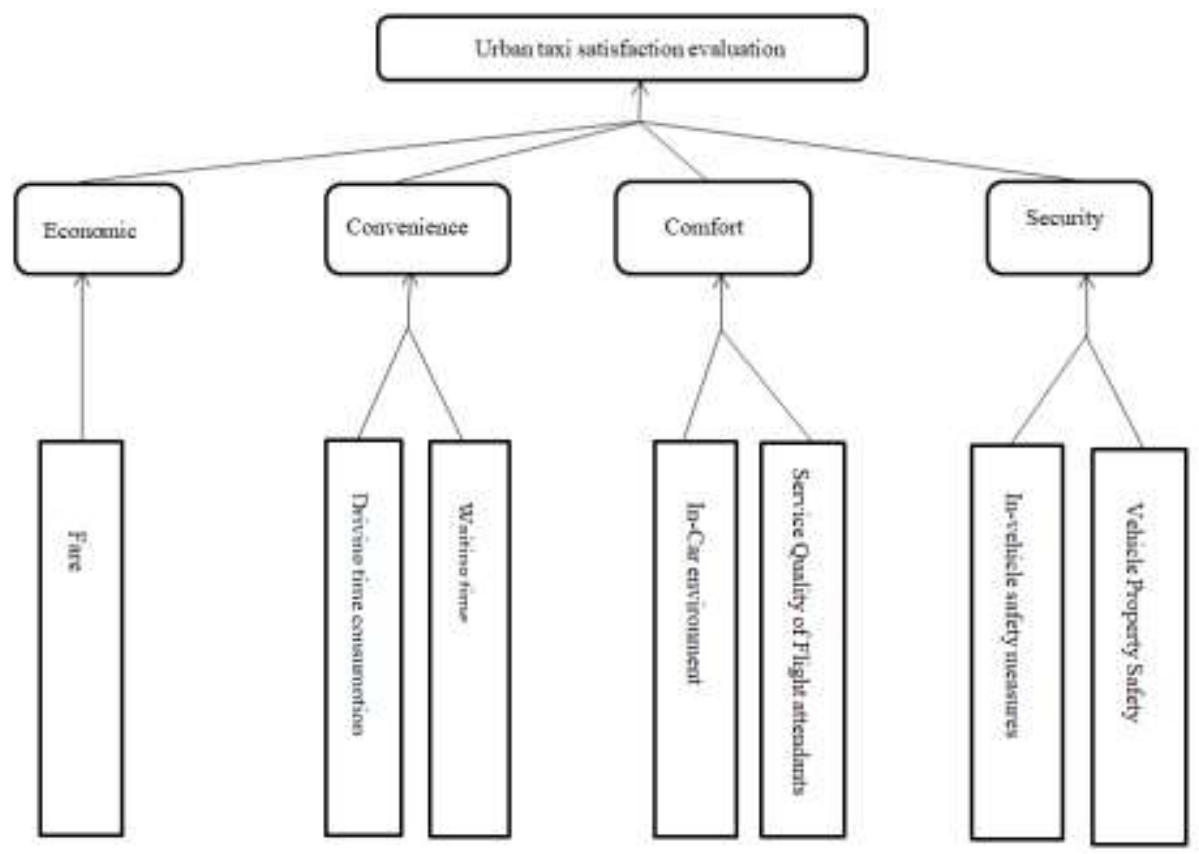

Fig. 2. A hierarchical analysis model for taxis.

Analytic Hierarchy Process (AHP) is to divide the elements which are always related to decision into three levels- target layer, criterion layer and scheme layer. For this analysis, only the target layer and benchmark layer are involved, and the criterion layer is divided into first-level index and two-grade index.

The satisfaction degree of urban public transport is divided into 4 first-level indicators and the satisfaction of urban public transport is investigated from the aspects of economy, convenience, comfort and safety, which consist of 10 secondary indexes to ensure a scientific and comprehensive evaluation of the target layer.

- Building a judgment matrix

In the process of establishing a judgment matrix, we use the YAAHP Group decision function for software, inviting 4 experts to evaluate the relative importance of each factor and construct five judgment matrices. 
Aij =1,3,5,7,9 (2,4,6,8 indicates adjacent median)

represents the importance of the $\mathrm{i}$ element relative to the $\mathrm{j}$ element (1 means equally important, 3 represents a little important,5 means more important,and7 means very important,9 Absolute importance) The opposite is the reciprocal.

According to 4 experts' score, we use weights weighted arithmetic averages to represent the final Judgment matrix.

- Calculate Weights

Through YAAHP Software, we calculate the weight of the bus, subway and taxi factors.

\section{Establishment of Multilevel Fuzzy Comprehensive \\ Evaluation Method}

Fuzzy comprehensive evaluation is a comprehensive evaluation method based on fuzzy mathematics. According to the membership grade of fuzzy Mathematics, the comprehensive evaluation transforms qualitative evaluation into quantitative evaluation, and that is, to make a general evaluation of things or objects restricted by many factors by fuzzy mathematics. It has the characteristics of clear result and strong system, and it can solve the problems which are vague and difficult to quantify, suitable for solving all kinds of non-deterministic problems.

- To count the previous questionnaires, and to count the percentages of each option.

- Establishment of three different modes of public transport satisfaction evaluation system and questionnaire score:

TABLE III. SATISFACTION EVALUATION SYSTEM AND THE SCORE OF QUESTIONNAIRE

\begin{tabular}{|c|c|c|c|c|c|c|c|c|}
\hline \multirow{11}{*}{ Bus } & $\begin{array}{l}\text { First-level } \\
\text { indicators }\end{array}$ & Level-two indicators & Proportion & $\begin{array}{c}\text { Very } \\
\text { satisfied }\end{array}$ & Satisfaction & So so & Dissatisfied & $\begin{array}{c}\text { Very } \\
\text { dissatisfied }\end{array}$ \\
\hline & \multirow{3}{*}{$\begin{array}{l}\text { Convenience } \\
(0.565)\end{array}$} & Driving time consumption & $63.49 \%$ & 0.023 & 0.155 & 0.496 & 0.258 & 0.068 \\
\hline & & Waiting time & $28.73 \%$ & 0.011 & 0.212 & 0.500 & 0.227 & 0.049 \\
\hline & & number of meters sites & $7.79 \%$ & 0.045 & 0.432 & 0.451 & 0.049 & 0.023 \\
\hline & \multirow{4}{*}{$\begin{array}{l}\text { Comfort } \\
(0.1175)\end{array}$} & Compartment congestion & $56.26 \%$ & 0.004 & 0.129 & 0.439 & 0.311 & 0.117 \\
\hline & & $\begin{array}{lcc}\text { Seating } & \text { number } & \text { and } \\
\text { seating arrangement } & \end{array}$ & $20.6 \%$ & 0.034 & 0.299 & 0.500 & 0.129 & 0.038 \\
\hline & & In-Car environment & $14.47 \%$ & 0.027 & 0.155 & 0.481 & 0.273 & 0.064 \\
\hline & & $\begin{array}{l}\text { Service Quality of Flight } \\
\text { attendants }\end{array}$ & $8.77 \%$ & 0.015 & 0.299 & 0.504 & 0.148 & 0.034 \\
\hline & $\begin{array}{l}\text { Economics } \\
(0.0553)\end{array}$ & Fare & $100 \%$ & 0.091 & 0.436 & 0.405 & 0.053 & 0.015 \\
\hline & \multirow{2}{*}{$\begin{array}{l}\text { Security } \\
(0.2622)\end{array}$} & In-vehicle safety measures & $50 \%$ & 0.061 & 0.311 & 0.477 & 0.125 & 0.027 \\
\hline & & Vehicle Property Safety & $50 \%$ & 0.034 & 0.212 & 0.553 & 0.170 & 0.030 \\
\hline \multirow{11}{*}{$\begin{array}{l}\text { Sub } \\
\text { way }\end{array}$} & $\begin{array}{l}\text { First-level } \\
\text { indicators }\end{array}$ & Level two indicators & Proportion & $\begin{array}{c}\text { Very } \\
\text { satisfied }\end{array}$ & Satisfaction & So so & Dissatisfied & $\begin{array}{c}\text { Very } \\
\text { dissatisfied }\end{array}$ \\
\hline & \multirow{3}{*}{$\begin{array}{l}\text { Convenience } \\
(0.565)\end{array}$} & Driving time consumption & $63.49 \%$ & 0.114 & 0.606 & 0.246 & 0.027 & 0.008 \\
\hline & & Waiting time & $28.73 \%$ & 0.121 & 0.553 & 0.277 & 0.038 & 0.011 \\
\hline & & $=$ number of meters sites & $7.79 \%$ & 0.068 & 0.379 & 0.413 & 0.114 & 0.027 \\
\hline & \multirow{4}{*}{$\begin{array}{l}\text { Comfort } \\
(0.1175)\end{array}$} & Compartment congestion & $56.26 \%$ & 0.034 & 0.239 & 0.417 & 0.250 & 0.061 \\
\hline & & \begin{tabular}{lcc|} 
Seating & number & and \\
seating arrangement & \\
\end{tabular} & $20.6 \%$ & 0.072 & 0.458 & 0.326 & 0.117 & 0.027 \\
\hline & & In-Car environment & $14.47 \%$ & 0.068 & 0.466 & 0.371 & 0.083 & 0.011 \\
\hline & & $\begin{array}{l}\text { Service Quality of Flight } \\
\text { attendants }\end{array}$ & $8.77 \%$ & 0.080 & 0.572 & 0.314 & 0.019 & 0.015 \\
\hline & $\begin{array}{l}\text { Economics } \\
(0.0553)\end{array}$ & Fare & $100 \%$ & 0.076 & 0.420 & 0.413 & 0.076 & 0.015 \\
\hline & \multirow{2}{*}{$\begin{array}{l}\text { Security } \\
(0.2622)\end{array}$} & In-vehicle safety measures & $50 \%$ & 0.080 & 0.530 & 0.337 & 0.042 & 0.011 \\
\hline & & $\begin{array}{l}\begin{array}{l}\text { Safety of property in } \\
\text { vehicle }\end{array} \\
\end{array}$ & $50 \%$ & 0.042 & 0.383 & 0.515 & 0.053 & 0.008 \\
\hline
\end{tabular}




\begin{tabular}{|c|c|c|c|c|c|c|c|c|}
\hline \multirow{8}{*}{ Taxi } & $\begin{array}{l}\text { First-level } \\
\text { indicators }\end{array}$ & $\begin{array}{l}\begin{array}{l}\text { Level two } \\
\text { indicators }\end{array} \\
\end{array}$ & Proportion & $\begin{array}{c}\begin{array}{c}\text { Very } \\
\text { satisfied }\end{array} \\
\end{array}$ & Satisfaction & So so & Dissatisfied & $\begin{array}{c}\text { Very } \\
\text { dissatisfied }\end{array}$ \\
\hline & \multirow{2}{*}{$\begin{array}{l}\text { Convenience } \\
(0.5048)\end{array}$} & $\begin{array}{l}\text { Driving time } \\
\text { consumption }\end{array}$ & $68.85 \%$ & 0.045 & 0.341 & 0.470 & 0.117 & 0.027 \\
\hline & & Waiting time & $31.15 \%$ & 0.049 & 0.254 & 0.553 & 0.106 & 0.038 \\
\hline & \multirow[b]{2}{*}{$\begin{array}{l}\text { Comfort } \\
(0.1431)\end{array}$} & $\begin{array}{l}\text { In-Car } \\
\text { environment }\end{array}$ & $62.27 \%$ & 0.023 & 0.269 & 0.568 & 0.095 & 0.045 \\
\hline & & $\begin{array}{lr}\text { Service } & \text { Quality } \\
\text { of } & \text { Flight } \\
\text { attendants } & \\
\end{array}$ & $37.73 \%$ & 0.027 & 0.303 & 0.530 & 0.102 & 0.038 \\
\hline & $\begin{array}{l}\text { Economics } \\
(0.0645)\end{array}$ & Fare & $100 \%$ & 0.027 & 0.129 & 0.500 & 0.235 & 0.110 \\
\hline & \multirow[b]{2}{*}{$\begin{array}{l}\text { Security } \\
(0.2876)\end{array}$} & $\begin{array}{l}\text { In-vehicle safety } \\
\text { measures }\end{array}$ & $50 \%$ & 0.027 & 0.280 & 0.515 & 0.125 & 0.053 \\
\hline & & $\begin{array}{ll}\begin{array}{l}\text { Safety } \\
\text { property }\end{array} & \text { of } \\
\text { vehicle } & \text { in } \\
\end{array}$ & $50 \%$ & 0.042 & 0.405 & 0.477 & 0.049 & 0.027 \\
\hline
\end{tabular}

Based on the weight of AHP hierarchy model, it can be seen that the first-level weight index of public transport is:

$$
A=[0.565,0.1175,0.2622,0.0553]
$$

The two-level indicator weights are:

$$
\begin{aligned}
& A_{1}=[0.6349,0.2873,0.079] \\
& A_{2}=[0.5626,0.2060,0.1447,0.0877] \\
& A_{3}=[1] \\
& A_{4}=[0.5,0.5]
\end{aligned}
$$

Using MATLAB, the first level fuzzy comprehensive evaluation of each child factor set is obtained: $B_{1}=A_{1} \bullet R_{1}=[0.0213,0.1930,0.4936,0.2328,0.0149]$

$B_{2}=A_{2} \bullet R_{2}=[0.0145,0.1830,0.4643,0.2543,0.0860]$

$B_{3}=A_{3} \bullet R_{3}=[0.011,0.436,0.405,0.053,0.015]$

$B_{4}=A_{4} \bullet R_{4}=[0.0475,0.2615,0.5150,0.1475,0.0285]$

In this way, the two-level comprehensive evaluation is: $C_{1}=A \bullet B=[0.0268,0.2232,0.4909,0.2030,0.0607]$
Similarly, the secondary comprehensive evaluation of metro and taxi is as follows: $C_{2}=[0.0897,0.5075,0.3309,0.0585,0.0142]$ $C_{3}=[0.0397,0.2846,0.5243,0.1089,0.0426]$

Finally, the results of comprehensive evaluation can be seen that the degree of the respondents' satisfaction to the bus, subway, taxi is mostly concentrated in average, satisfactory, average. Because the score is abstract and has a great sense of subjectivity, the results of the comprehensive evaluation are quantified below.

\section{- To calculate overall satisfaction scores}

To sum up, according to the degree of the questionnaire, the score of 5 is very satisfactory and so on, the score of 1 represents dissatisfied, the comprehensive score of three different types of public transport can be achieved:

TABLE IV. COMPREHENSIVE GRAdING OF BUSES, SubWAYS AND TAXIS

\begin{tabular}{|c|l|l|}
\hline Type & Two-level comprehensive evaluation & $\begin{array}{l}\text { Comprehensive } \\
\text { score }\end{array}$ \\
\hline Bus & $C_{1}=[0.0268,0.2232,0.4909,0.2030,0.0607]$ & 2.9662 \\
\hline Subway & $C_{2}=[0.0897,0.5075,0.3309,0.0585,0.0142]$ & 3.6024 \\
\hline Taxi & $C_{3}=[0.0397,0.2846,0.5243,0.1089,0.0426]$ & 3.1702 \\
\hline
\end{tabular}

From the table, we can draw that the Metro's satisfaction score is significantly larger than that of buses and taxis, which is 3.6024; the score is between satisfaction and average, but the satisfaction is biased, which indicates that the public satisfaction with the subway is in a relatively satisfactory state. The satisfaction score of the taxi is slightly higher than that of the bus, and the satisfaction scores of the two are 3.1702 and 2.9662 respectively. Thus it can be seen that the satisfaction of bus and taxi among the masses is more average. The overall satisfaction of Wuhan public transport is in the middle level, of which the subway is the best. The government should increase the investment and improvement of bus and taxi to enhance the residents ' satisfaction.

\section{CONCLUSION}

Through the above research we can conclude that: 1 . in three major public transport vehicles, the subway gets the highest score 2 . Bus and subway have become the main force of public transport in Wuhan. 3. Residents think convenience is the most important indicator of public transport 4. Bus, subway, taxi advantages are economic, convenient, safe 5. The elderly and those who have annual income of 80000 to 140 000RMB have the highest level of satisfaction with public transport 6 . High-income groups pay more attention to convenience, and lower-income people pay more attention to economy 7. Elderly pay more attention to economy, the young pay more attention to convenience 


\section{REFERENCES}

[1] Lee Roming . study on traffic congestion in Wuhan city [D]. Wuhan University of University, A.

[2] Deng Juan , Zhang, Ching Flat, Shao Qinfang , Lo Xudong . urban traffic congestion and sustainable development: A case study of Wuhan City [J]. Technology Entrepreneurship Monthly, 35-37.

[3] Gall, Zhao . the causes and countermeasures of urban traffic congestion from the point of view of scarcity of space resources [J]. Productivity Research, 2007 , ( 6 ): 88-89

[4] Weibenge. Research on traffic problem solving strategies in China's metropolitan areas--from the angle of traffic supply and traffic demand ; [J]. City Issues, 1998 (5): 38-41.

[5] Vurong, Zhai Building, Shong, Lili . Urban Public Transport Service satisfaction assessment model [N]. Journal of Transport Engineering, 2009-08-09.

[6] Xu Huicai . Research on government performance evaluation oriented by satisfaction [D]. Southwest University of Finance and economics

[7] Wu Hongyang, Shen Lijun, Sun Liying, Jiang Yulin . Urban Traffic satisfaction Assessment model construction and empirical test . Chinese and foreign highways , 2008,28 (6).

[8] Paul A Samuelson. Germ of public expenditure[J]. The Review of Economics Statistics, 1954, 36 (4): 387-389.

[9] Shing, Wu Ping, Chong . study on the behavior of urban public transport travel mode selection [J]. Journal of Wuhan University of Technology (Traffic Science and Engineering edition ). 2013,37 (2): 352-356. (

[10] Chen . A summary of priority urban public transport in Hubei province [J]. People's Bus .2011

[11] Zhou, Tri Shenhui, Yong, Song Xiaodong ,. Satisfaction analysis of urban public transport - Xiamen Island For example [J]. Urban Development Research 2011-01-26,18 (1): 74-80.

[12] Ouyang Chenhai, Wu Haiyan, Tommy. , , . Beijing public transport commuters ' satisfaction study [J]. Road Traffic and security , 200710-15,7 (5): 37-43.

[13] $\mathrm{Li} \mathrm{Yi}$. evaluation of satisfaction degree and network structure of public transport service in the main urban area of Changsha [D]. Hunan University. 